\title{
RADIOCARBON DATING WITH TANDEM ELECTROSTATIC ACCELERATORS
}

\author{
H E GOVE, DAVID ELMORE, and R D FERRARO*
}

and

\author{
R P BEUKENS, K H CHANG, L R KILIUS, \\ H W LEE, and A E LITHERLAND**
}

and

\section{K H PURSER*** and MEYER RUBIN 9}

\begin{abstract}
An MP tandem Van de Graaff accelerator at the University of Rochester has been employed since May 1977 to detect ${ }^{14} \mathrm{C}$ in various terrestrial samples. The carbon sample sizes required are $\mathrm{lmg}$ or less. Dating accuracies based on reproducibility now approach ( \pm 80 years). Measurements have been made on 1850 wood, Australian sucrose, a carbon sample from Mt Shasta, a baby woolly mammoth, and an Egyptian bull mummy wrapping.
\end{abstract}

\section{INTRODUCTION}

In this paper, a direct radioisotope detection technique using a tandem electrostatic accelerator is described and results on ${ }^{14} \mathrm{C}$ are summarized. It was first employed by Purser and others (1977) and Bennett and others (1977) at Rochester to measure ${ }^{14} \mathrm{C}$ from natural carbonaceous samples and from infinitely old samples (graphite) in May 1977. The method has been rapidly developed since then at the University of Rochester by Bennett and others (1978) and Gove and others (1979) and elsewhere (Gove, 1978; Nelson, Korteling, and Stott, 1977; Muller, Stephenson, and Mast, 1978; Stephenson, Mast, and Muller, 1979). The advantages of direct detection was pointed out by Oeschger and others (1970). The idea of using accelerators as ultrasensitive mass spectrometers was conceived independently by Purser (1976) and Muller (1977). The specific suggestion of applying a cyclotron to directly detect ${ }^{14} \mathrm{C}$ and other radioisotopes was first published by Muller (1977).

\section{Experimental procedures}

In a recent review paper (Purser, Litherland, and Gove, 1979) the use of a tandem electrostatic accelerator as an ultra-sensitive particle identifier was described in some detail. The system presently in use at the University of Rochester is shown schematically in figure 1. The material in which a specific radioisotope is to be detected is inserted as a solid in the sample wheel of a cesium sputter ion source (Model 834 HICONEX, General Ionex Corp, Newburyport, Massachusetts) of the Middleton (1977) design. A $20 \mathrm{keV}$ cesium beam impinges on the ion source material in the reflected Cs + beam geometry (Brand, 1977). The $20 \mathrm{keV}$ negative ions, so produced, are extracted and momentum analyzed

* Nuclear Structure Research Laboratory, University of Rochester, Rochester, New York 14627 $1 \mathrm{~A} 7$

** Department of Physics, University of Toronto, Toronto, Ontario, Canada M5S

*** General Ionex Corporation, 19 Graf Road, Newburyport, Massachusetts 01950

I Radiocarbon Laboratory, US Geological Survey, Reston, Virginia 20922 
in a $35^{\circ}$ inflection magnet with a mass resolution $M / \Delta M=25$. They are further accelerated through $150 \mathrm{kV}$ and injected into the Rochester MP tandem Van de Graaff accelerator. A typical current output from the ion source as a function of the field of the inflection magnet is shown in figure 2. In this particular case, the ion source sample was carbon. Ion masses from 12 to 19 can be identified. A possible explanation for the peak labeled ${ }^{12} \mathrm{C}^{-*}$ is given in Purser, Litherland, and Gove (1979). The major contribution to the mass 14 peak comes from the molecules ${ }^{12} \mathrm{CH}_{2}{ }^{-}$ and ${ }^{13} \mathrm{CH}^{-}$. The ${ }^{14} \mathrm{C}^{-}$contribution to this peak is miniscule. The negative molecules and atoms are then accelerated through the first half of the tandem electrostatic accelerator, the terminal voltage of which has been set to a value appropriate to the particular ion under study and the charge state to be selected in the final analysis system. A differentially pumped gas cell in the terminal strips the ions of several electrons and also serves to dissociate molecules. The multiply charged positive ions are then accelerated through the second half of the tandem. A specific mass energy product $\left(\mathrm{ME} / \mathrm{Q}^{2}\right)$ is selected by the $90^{\circ}$ analyzing magnet $(\mathrm{P} / \Delta \mathrm{P}=600)$ and $45^{\circ}$ deflecting magnet (which served to eliminate scattered particles). A $10^{\circ}$ electrostatic analyzer $(\mathrm{E} / \Delta \mathrm{E}=200)$ serves to define $\mathrm{E} / \mathrm{Q}$ so that the ions entering the final detector have unique values of $\mathrm{M} / \mathrm{Q}$ or, what is equivalent, have uniquely defined velocities. The final detector was developed (Shapira and others, 1975) for heavyion nuclear physics research at Rochester as a magnetic spectrometer focal plane detector. It was modified for the work discussed here as described in Purser, Litherland, and Gove (1979). This gas-filled counter provides several $\mathrm{dE} / \mathrm{dx}$ signals from separate electrodes along the path of the ion as well as the total energy deposited. When the velocity of the ions incident on the counter is defined, a measurement of $\mathrm{dE} / \mathrm{dx}$ defines the ion's nuclear charge $\mathrm{Z}$.



Fig 1. A schematic diagram of the system presently employed at Rochester for ultrasensitive mass spectrometry. 
The advantages of this tandem electrostatic technique in its use of negative ions, terminal molecular dissociation, and sufficient energy for $\mathrm{Z}$ definition, when required will be discussed below only for the case of ${ }^{14} \mathrm{C}$, although the system has also been used to measure the radioisotopes ${ }^{10} \mathrm{Be},{ }^{26} \mathrm{Al}$ and ${ }^{36} \mathrm{Cl}$.

\section{RESULTS}

The intial radiocarbon measurements at Rochester (Purser and others, 1977; Bennett and others, 1977) were followed by measurements (Bennett and others, 1978) of carbon samples ranging in age from 200 to 40,000 years, as dated by the US Geological Survey in Reston, Virginia. In these early measurements, the final electrostatic deflector had not yet been installed and the measurements were made with the Rochester heavy-ion detector located in the focal plane of a split-pole magnetic spectrometer. Figure 3 shows a three-dimensional plot of the output from this detector when a USGS sample from Mt Shasta dated at $4590 \pm 250$ years old was run in the ion source. The two parameters $\mathrm{E}_{\text {TOTAL }}$ and $\mathrm{E}_{\text {FINAL }}$ refer to the signals from the detector corresponding to the total energy deposited in the detector from the ions and the energy from some fraction of the track near the end of its range. The peaks are plotted on a logarithmic scale. The carbon ion energy was $40 \mathrm{MeV}$. The ${ }^{13} \mathrm{C}$ and ${ }^{12} \mathrm{C}$ peaks come from ${ }^{12} \mathrm{CH}_{2}-$ and ${ }^{13} \mathrm{CH}^{-}$molecules from the source, which are dissociated in the terminal and then undergo improbable charge changes during their acceleration in the second half of

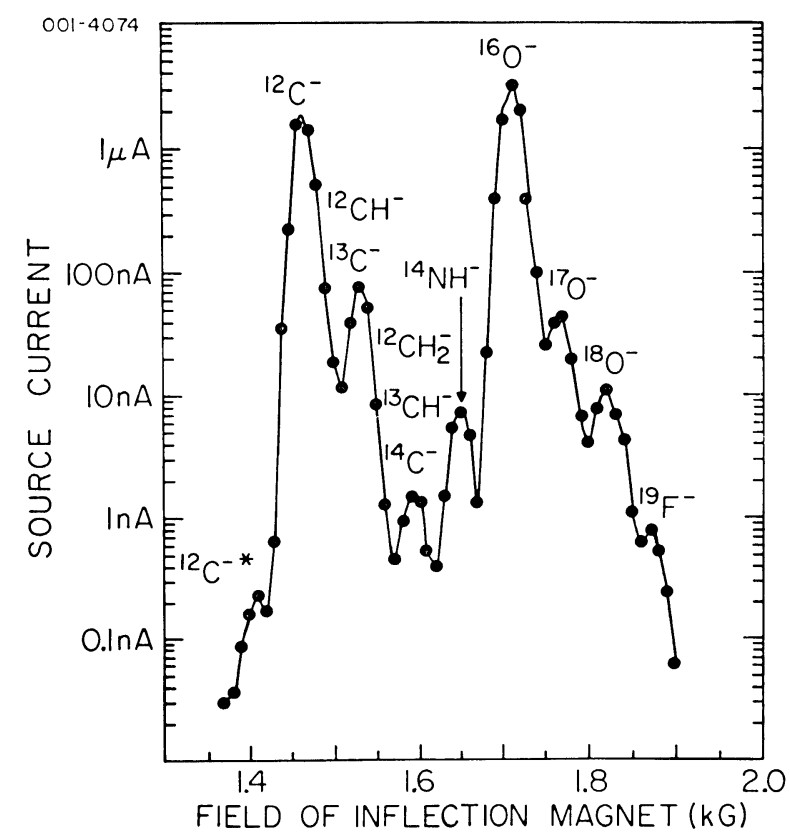

Fig 2. Output of the negative ion beams from the sputter source using a carbon sample. The ions have an energy of $20 \mathrm{keV}$ and are magnetically analyzed. 
the tandem, so that they have the same $M E / Q^{2}$ as the ${ }^{14} \mathrm{C}$ ions. They serve no useful purpose and can be eliminated with an electrostatic deflector. The ${ }^{14} \mathrm{~N}$ peak in the spectrum does not arise from ${ }^{14} \mathrm{~N}-$ ions from the source. One of the first measurements made at Rochester (Purser and others, 1977) was to demonstrate what had long been suspected, that ${ }^{14} \mathrm{~N}$ - is too unstable to survive acceleration through the tandem. For this reason, the use of a device such as a tandem electrostatic accelerator that starts with negative ions is one of the keys to success of the technique as far as ${ }^{14} \mathrm{C}$ measurements are concerned (Bennett and others, 1977). During these early runs, it was shown that if only the extra electron that produced negative molecules (eg, $\mathrm{CH}^{-}$and $\mathrm{CH}_{2}{ }^{-}$) and two additional electrons were removed in the terminal stripper to yield $\mathrm{CH}_{2}{ }^{+2}$ and $\mathrm{CH}^{+2}$, the molecules were sufficiently stable to allow a fraction of them to survive to the detector (Gove and others, 1979). If, however, one chooses $\mathrm{CH}_{2}{ }^{+3}$ and $\mathrm{CH}^{+3}$, the molecules dissociate completely before reaching the detectors. In all the work at Rochester, atomic charge states of +3 or greater are employed and molecular interference is eliminated. This, incidentally, sets the minimum voltage on the terminal of a tandem electrostatic accelerator designed specifically as a dedicated ${ }^{14} \mathrm{C}$ measuring device at about 2.5 MV because that represents the peak in the production of carbon atoms in the +3 charge state.

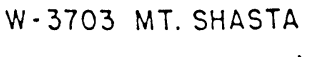

$4590 \pm 250$ yrs.(USGS)

13



Fig 3. A two parameter logarithmic plot (3 decades) of the counts in the final heavy ion detector. Only magnet analysis was employed. A natural carbon sample (Mt Shasta) supplied the negative ions from the sputter source. 
The dramatic improvement achieved (Gove and others, 1979) when an electrostatic deflector was added and the multi-parameter heavy-ion detector was installed directly following it (see fig 1), is shown in figure 4. Again, the Mt Shasta carbon sample was employed. The ungated spectrum shown in the upper half of the figure demonstrates that the ${ }^{13} \mathrm{C}$ peak which is so prominent in figure 3 is now virtually eliminated. The ${ }^{7} \mathrm{Li}$ peak arises from ${ }^{7} \mathrm{Li}_{2}-$ molecules from the source dissociating in the terminal stripper into ${ }^{7} \mathrm{Li}^{2+}$ ions. These are only distinguishable from the ${ }^{14} \mathrm{C}^{-}$ions from the source converting to ${ }^{14} \mathrm{C}^{+4}$ ions in the terminal because they have a different $\mathrm{Z}$ and, hence, a different $\mathrm{dE} / \mathrm{dx}$. The ${ }^{2} \mathrm{Li}$ peak arises when two ${ }^{7} \mathrm{Li}$ ions enter the detector, simultaneously. If either charge 3 or 5 had been selected, these lithium peaks would have been eliminated. Again, the small ${ }^{14} \mathrm{~N}$ and ${ }^{13} \mathrm{C}$ peaks come from negative

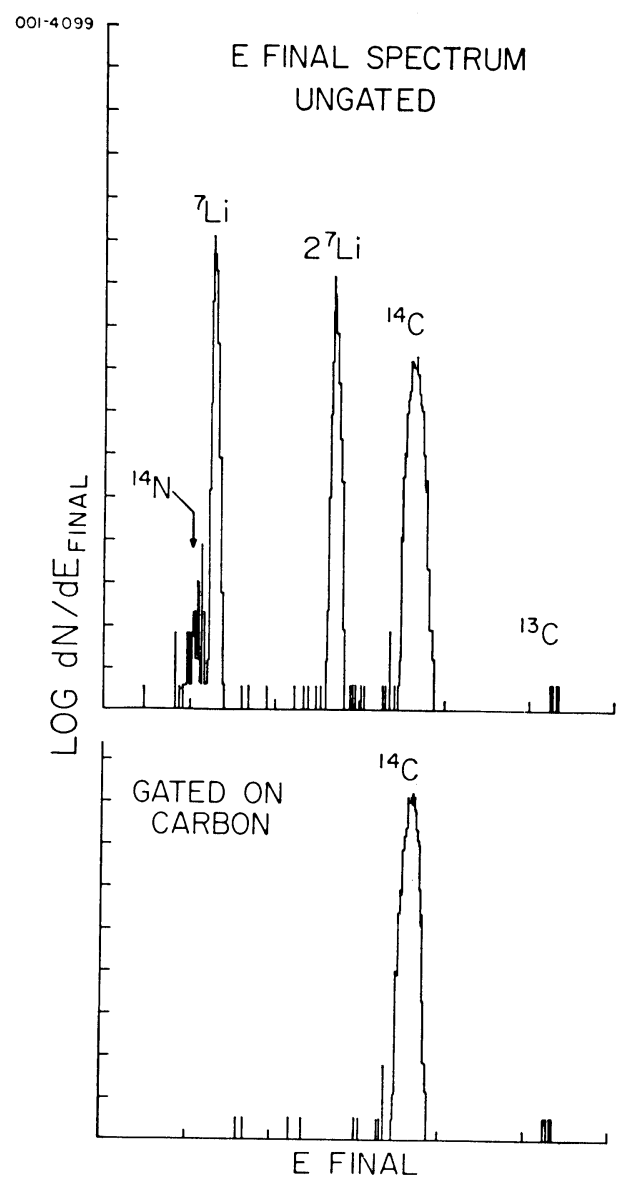

Fig 4. Spectra of the logarithm of counts as a function of the energy lost in the final section of the heavy-ion detector $\left(\mathrm{E}_{\mathrm{FINAL}}\right)$. Now both magnetic and electric deflection is employed as in figure 1 . The sample is the same as that for figure 3 (Mt Shasta). 
ion molecular hydrides from the source which undergo improbable increases or decreases in charge and slip through to the detector.

In the original measurements the source material was amorphous carbon mixed with an equal amount of $\mathrm{KBr}$ which served as a binder. This was pressed into the aluminum cylinder which was mounted on the negative ion source wheel. The recent measurements reported below used a mixture of amorphous carbon and finely powdered metallic silver or copper. This was pressed into a $2 \mathrm{~mm}$ diameter shallow re-entrant hole in the aluminum cylinder. Carbon weights involved in the sample ranged from less than $1 \mathrm{mg}$ to $10 \mathrm{mg}$, although, in general, most of the material still remained after the measurement was completed. Work is under way at several laboratories to crack carbon from methane or acetylene onto metal backings which can be mounted on the source wheel. This will substantially increase the ${ }^{12} \mathrm{C}$ beams from the sample which are presently limited to a few microamperes.

In recent ${ }^{14} \mathrm{C}$ measurements at Rochester, the measurement technique employed was to cycle the ion source inflection magnet and the $90^{\circ}$ analyzing magnet between masses 12,13 , and 14 on a few minute time scale keeping the terminal voltage and the electrostatic deflector voltage fixed. A generating voltmeter stabilizing system was used to keep the terminal voltage constant to within $\pm 2 \mathrm{keV}$. The mass 12 and 13 carbon beams are measured in a Faraday cup following the $90^{\circ}$ analyzing magnet while the ${ }^{14} \mathrm{C}$ is counted in the heavy ion detector. To avoid loading problems when the magnets are set for ${ }^{12} \mathrm{C}$, an attenuator which reduces the ${ }^{14} \mathrm{C}$ beam by about a factor of 10 is inserted near the ion source end of the system. Using this technique, the accuracy of the measurements now approaches 1 percent ( \pm 80 years).

Some of the recent ${ }^{14} \mathrm{C}$ results at Rochester are listed in table 1 . The accuracy with which the Mt Shasta samples can now be measured based on reproducibility (the so-called external error) approaches 1 percent.

Table 1

Recent ${ }^{14} \mathrm{C}$ results from Rochester

\begin{tabular}{|c|c|c|}
\hline Sample & $\begin{array}{l}\text { Rochester age } \\
(\text { years BP) }\end{array}$ & Expected age \\
\hline Mt Shasta & $4580 \pm 90$ & $4590 \pm 250 * *$ \\
\hline $\begin{array}{c}\text { Bull mummy } \\
\text { cloth } \\
\text { Dahshur, Egypt }\end{array}$ & $2200 \pm 150$ & $2050 \pm 200 * *$ \\
\hline $\begin{array}{l}\text { Baby woolly } \\
\text { mammoth } \\
\text { (USSR) }\end{array}$ & $27,000 \pm 1000$ & $\begin{array}{l}\text { Available sample } \\
\text { size too small to } \\
\text { date by conventional } \\
\text { methods }\end{array}$ \\
\hline $\begin{array}{l}\text { Australian } \\
\text { sucrose }\end{array}$ & $1.47 \pm 0.03 \dagger$ & $1.45-1.51_{+}^{+}$ \\
\hline
\end{tabular}

$*_{\mathrm{BP}}=$ years before $1950 .{ }^{14} \mathrm{C}$ half-life assumed to be 5568 years

** As measured by the USGS wood.

† This is the ratio of ${ }^{14} \mathrm{C} /{ }^{12} \mathrm{C}$ in the sucrose standard to the ${ }^{14} \mathrm{C} /{ }^{12} \mathrm{C}$ ratio in 1950

$\ddagger$ Measurements of this ratio from other laboratories fall in this range. 
This is a substantial improvement over the 5 percent values previously reported (Bennett and others, 1979). The source preparation technique used for the Egyptian bull mummy wrapping and the subsequent age measurement is the same as could be employed for dating any precious linen artifact such as the Shroud of Turin.

In June 1977 an intact, completely frozen baby mammoth (named Dima) was uncovered by a bulldozer operator in the Magadan region of northeastern Siberia. A sample of $1.3 \mathrm{~g}$ of muscle was made available to M Goodman of the Anatomy Department of Wayne State University's School of Medicine. At his request, a sample of about $0.9 \mathrm{mg}$ of carbon (obtained from about 4mg of muscle) was dated and the age shown in table 1 was measured. This is a preliminary result and another measurement will be made.

Finally, in table 1, are shown the Rochester results for an Australian sucrose sample under consideration for a new contemporary standard. It is being measured by all the major radiocarbon dating laboratories. The ${ }^{14} \mathrm{C} /{ }^{12} \mathrm{C}$ ratio (compared with that for the ratio in $\mathrm{AD} 1950$ ) is shown along with an indication of the range of values obtained at other laboratories. The sample sizes employed in the measurements summarized in table 1 ranged from about 1 to $10 \mathrm{mg}$.

\section{Future prospects}

The Rochester system will continue to measure a limited number of carbonaceous samples of significant importance. It will also continue to measure the radioisotopes ${ }^{10} \mathrm{Be},{ }^{26} \mathrm{Al}$ and ${ }^{36} \mathrm{Cl}$ in various natural samples of interest. The sensitivity that has presently been achieved for measuring these three radioisotopes and ${ }^{14} \mathrm{C}$ at Rochester is shown in table 2. In this connection, an interesting area that can be explored involves the measurement of the ratio ${ }^{26} \mathrm{Al} /{ }^{10} \mathrm{Be}$ in marine sediments. It was pointed out by Lal (1962) that this ratio which has an effective half-life of 1.30 million years should be independent of cosmic ray flux and, thus, should provide an absolute chronology on a few-million-year time scale. The Rochester system is presently unique in its ability to

TABle 2

Sensitivity data

\begin{tabular}{|c|c|c|c|}
\hline $\begin{array}{l}\text { Radio- } \\
\text { isotope }\end{array}$ & Samples & Ratio & $\begin{array}{l}\text { Minimum } \\
\text { measured value } \\
\text { of ratio }\end{array}$ \\
\hline${ }^{14} \mathrm{C}$ & Graphite & ${ }^{14} \mathrm{C} /{ }^{12} \mathrm{C}$ & $(3 \pm 2) \times 10^{-16}$ \\
\hline${ }^{36} \mathrm{Cl}$ & $\begin{array}{l}\text { AgCl from } \\
\text { reagent } \\
\text { grade } \\
\mathrm{NH}_{4} \mathrm{Cl}\end{array}$ & ${ }^{36} \mathrm{Cl} / \mathrm{Cl}$ & $<2 \times 10^{-16}$ \\
\hline${ }^{10} \mathrm{Be}$ & $\begin{array}{l}\text { Spectro- } \\
\text { scopically } \\
\text { pure Be }\end{array}$ & ${ }^{10} \mathrm{Be} / \mathrm{Be}$ & $(7 \pm 3) \times 10^{-15}$ \\
\hline${ }^{26} \mathrm{Al}$ & $\begin{array}{l}\text { Pure Al } \\
99.999 \%\end{array}$ & ${ }^{26} \mathrm{Al} / \mathrm{Al}$ & $<10^{-14}$ \\
\hline
\end{tabular}


measure both ${ }^{10} \mathrm{Be}$ and ${ }^{26} \mathrm{Al}$ in the same sample. The ability of the technique to measure other isotopes, both radioactive and stable, will be explored as well as its application to various areas of basic nuclear research.

Less than two years after the first Rochester results, funding has been approved for three systems based on the tandem electrostatic accelerator principle (Purser and Hanley, 1978) which will be dedicated to the direct detection of both radioactive and stable isotopes. Two of these, at the University of Arizona and Oxford University, will be primarily used for ${ }^{14} \mathrm{C}$ detection. The third, at the University of Toronto, is being designed to detect a wide variety of isotopes and will, specifically, have important geophysical applications.

\section{AKNOWLEDGMENTS}

This work would not have been possible without the dedicated assistance of the accelerator staff of the University of Rochester's Nuclear Structure Research Laboratory. The laboratory's support by grants from the National Science Foundation is gratefully acknowledged. The University of Toronto is supported in part by a grant from the National Science and Engineering Research Council of Canada. Rolf P Beukens is a Killam Fellow.

\section{REFERENCES}

Bennett, C L, Beukens, R P, Clover, M R, Elmore, D, Gove, H E, Kilius, L R, Litherland, A E, and Purser, K H, 1978, Radiocarbon dating with electrostatic accelerators: Dating milligram samples: Science, v 201, p 345-347.

Bennett, C L, Beukens, R P, Clover, M R, Gove, H E, Liebert, R P, Litherland, A E, Purser, K H, and Sondheim, W E, 1977, Radiocarbon dating using electrostatic accelerators: Negative ions provide the key: Science, v 198, p 508-510.

Brand, K, 1977, The reflected beam sputter source: Nuclear Instruments and Methods, v 141, p 519-520.

Gove, H E, ed, 1978, Conference on radiocarbon dating with accelerators, 1st, Proc: Rochester, New York, Univ Rochester.

Gove, H E, Fulton, B R, Elmore, D, Litherland, A E, Beukens, R P, Purser, K H, and Naylor, H, 1979, Radioisotope detection with tandem electrostatic accelerators: IEEE Trans Nuclear Sci, v 26, p 1414-1419.

Lal, Devendra, 1962, Cosmic ray produced radionuclides in the sea: Jour Oceanog Soc, Japan, 20th anniv vol, p 600-614.

Middleton, R, 1977, A survey of negative ions from a cesium sputter source: Nuclear Instruments and Methods, v 114, p 373-399.

Muller, R A, 1977, Radioisotope dating with a cyclotron: Science, v 196, p 489-494.

Muller, R A, Stephenson, E J, and Mast, T S, 1978, Radioisotope dating with an accelerator: A blind measurement: Science, v 201, p 347-348.

Nelson, D E, Korteling, R G, and Stott, W R, 1977, Carbon-14: Direct detection at natural concentrations: Science, v 198, p 507-508.

Oeschger, Hans, Houtermans, J, Loosli, H H, and Wahlen, M, 1970, The constancy of cosmic radiation from isotope studies in meteorites and on the earth, in Olsson, I U, ed, Radiocarbon variations and absolute chronology, Nobel symposium 12, Proc: New York, John Wiley \& Sons, p 471-498.

Purser, K H, 1976, U S Patent 4,037,100. Filed March 1, 1976; issued July 19, 1977.

Purser, K H and Hanley, P R, 1978, A carbon dating system, in Gove, H E, ed, Conf on radiocarbon dating with accelerators, 1st, Proc: Rochester, New York, Univ Rochester, p 165-186.

Purser, K H, Liebert, R B, Litherland, A E, Beukens, R P, Gove, H E, Bennett, C L, Clover, M R, and Sondheim, W E, 1977, An attempt to detect stable $\mathrm{N}^{-}$ions from a sputter ion source and some implications of the results for the design of tandems for ultra-sensitive carbon analysis: Rev Phys Appl, v 12, p 1487-1492.

Purser, K H. Litherland, A E, and Gove, H E, 1979, Ultra-sensitive particle identification systems based upon electrostatic accelerators: Nuclear Instruments and Methods, v 162 , p 637-656. 
Shapira, D, DeVries, R M, Fulbright, H W, Tōke, J, and Clover, M R, 1975, The Rochester heavy-ion detector: Nuclear Instruments and Methods, v 129, p 123-130. Stephenson, E J, Mast, T S, and Muller, R A, 1979, Radiocarbon dating with an accelerator: Nuclear Instruments and Methods, v 158, p 571-577.

DISCUSSION

Grootes: I would like to comment on your statement that ${ }^{12} \mathrm{C}$ and ${ }^{13} \mathrm{C}$ entering the accelerator as ${ }^{12} \mathrm{CH}_{2}$ and ${ }^{13} \mathrm{CH}$ are eliminated by the terminal stripping process because energy is conserved. As Prof Schmidt will discuss in our paper this afternoon, charge exchange occurs in the high energy beam line, leading to a more or less continuous distribution of energy, for the positive ${ }^{12} \mathrm{C}$ and ${ }^{13} \mathrm{C}$ ions emerging from the accelerator. Therefore, although energy may be conserved, it is not well defined. The result is, that part of the ${ }^{12} \mathrm{C}$ and ${ }^{13} \mathrm{C}$ positive ions have the same magnetic rigidity as the ${ }^{14} \mathrm{C}$ ion $\left({ }^{14} \mathrm{C}^{+4}\right.$ in our case) selected. The ${ }^{14} \mathrm{C}$ beam arriving at the detector may thus still be heavily contaminated with ${ }^{12} \mathrm{C}$ and ${ }^{13} \mathrm{C}$ ions. The stripping process from $\mathrm{C}^{-}$to $\mathrm{C}^{+}{ }^{(4)}$ is, in itself, not sufficient to produce a clean ${ }^{14} \mathrm{C}$ beam.

Special precautions producing a very clean, hydrocarbon poor, sample (and ion source vacuum) as well as an additional cleanup of the beam in a Wien velocity filter or electrostatic deflector are, therefore, essential.

Secondly, I would like to comment on the way in which "background" measurements are used to estimate the range of the ${ }^{14} \mathrm{C}$ dating method using an accelerator. As you may well know, for proportional counters the background counting rate is generally of the order of 1 to $6 \mathrm{cpm}$, while the minimum sample activity that can reliably be measured is of the order of 0.05 to $0.10 \mathrm{cpm}$. This is possible thanks to the high stability of proportional counters. Under good operating conditions, Poisson counting statistics is the main factor determining the uncertainty. For ${ }^{14} \mathrm{C}$ counting by accelerator, $\mathrm{I}$ think the situation is quite different. In the first place it is not yet exactly known where the background counts come from.

1) If they originate from preparation of the background sample, the "background" ${ }^{14} \mathrm{C}$ count rate in samples may be different.

2) If they result from cross-contamination of the background sample in the ion source with material from other active samples, the ${ }^{~}{ }^{14} \mathrm{C}$ background" will depend on the previous measurements made and the sputtering away of the surface layer.

3) Only if the background counts originate in the accelerator in parts of the system that are not occasionally cleaned and changed, we can consider them a true background that may be stable.

The first task, therefore, is to find the origin of the ${ }^{14} \mathrm{C}$ background. Once the origin of the background is known, we have to estimate its uncertainty to find the minimum ${ }^{14} \mathrm{C}$ count rate that still can be measured reliably ( $2 \sigma$ criterion). This may be considerably lower but may also be higher than the observed ${ }^{14} \mathrm{C}$ background counting rate depending on the variability of the sample contamination 1) and 2) and the stability of the accelerator and its background contribution. Only in this way can we make a meaningful estimate of the age range for a particular dating facility. 